\title{
TEST ANXIETY, COMPUTER SELF EFFICACY, AND PERCEIVED EASE OF USE DURING COMPUTER-BASED TEST ON FIRST-YEAR STUDENTS
}

\author{
Endah Mastuti ${ }^{1 *}$ and Dewi Retno Suminar ${ }^{1}$ \\ ${ }^{1}$ Universitas Airlangga, Indonesia
}

\begin{abstract}
This study aims to provide description of psychological factors such as test anxiety, computer self-efficacy, and perceived ease of use in completing computer-based tests (CBT) on firstyear students. Such study is important because for first year students from different regions, not all of them have experience of CBT and there are possibilities of various psychological aspects such as CBT anxiety, Computer Self-Efficacy, and perceived ease of use affecting them in completing CBT. The subjects are 203 first-year students of Faculty of Psychology Universitas Airlangga. Scales used in this research include an adaptation of Computer Self-Efficacy scale by Compeau, DR, and Higgins, CA (1995), Test Anxiety Inventory (TAI) by Taylor and Diane (2002), Perceived Ease of Use scale by Davis (1989). The results showed that the student's test anxiety test during CBT are categorized as $16.74 \%$ low, $76.26 \%$ moderate and $7 \%$ high. Regarding computer self-efficacy, about $28.57 \%$ students had low efficacy, $59.60 \%$ with mediocre efficacy and $11.82 \%$ had high efficacy. In term of perceived ease of use of the CBT, $2.46 \%$ perceived low ease, $34,48 \%$ perceived moderate degree of ease, while $63,05 \%$ perceived high ease of use.
\end{abstract}

Keywords: Computer self-efficacy, test anxiety, perceived ease of use

\section{Introduction}

Technology advancement has been very rapid in the last decades. It certainly affects the human life both in daily activities and at work. Utilization of technology has a wide range of impacts and important roles. Universities are among the institutions which are expected to follow the advancement of technology, for instance by utilizing it for evaluation process. One instance of such application is the use of computer-based test (CBT) for assessment process.

As one of the new technology innovations, of course CBT is not easily accepted by test-takers. Similar to the emergence of other technology, it takes some influencing factors for CBT to be fully accepted. This phenomenon is explained by the Computer-Based Assessment (CBA) Acceptance model. This model explicates that CBA acceptance can be indicated by intention to use CBA. Further, intention to use CBA is influenced by some factors, such as perceived ease of use and perceived playfulness (Maqableh et al, 2015).

Some studies on CBT focused on the issue of equivalence by comparing the test score in CBT and in paperbased test (PBT). Other studies focused on the acceptance of CBT as a new technology. A research pertaining to CBA, in which CBT is one sort of CBA, by Terzis \& Economides (2011), proposed the Computer-Based Assessment Acceptance Model (CBAAM) and involved eight variables, namely content, perceived playfulness, perceived ease of use, perceived usefulness, goal expectancy, social influence, facilitating conditions, and selfefficacy in using computer. In addition, another study by Lu and colleagues (2016) found the effect of computer self-efficacy, training satisfaction, and test anxiety on attitudes towards and performance in computerized adaptive testing (CAT). 
Faculty of Psychology of Universitas Airlangga is among institutions that has been applied CBT since 2013. Some researches on the application of CBT have been conducted by author, including an initial survey in 2014 which found that $27 \%$ students agreed and $19 \%$ students strongly agreed that online test had caused students to be more anxious. This is in accordance with a research by Chua (2012) which found that anxiety in facing test had negative impact on the performance during Computer Adaptive Test (CAT). It means that lower anxiety is associated with higher test score and vice versa. Meanwhile, 24\% students were neutral, 16\% disagreed, and 13\% strongly disagreed that online test had made them more anxious (Mastuti, 2014). Further, a research by author in 2016 resulted in some findings as follow: (1) Self-efficacy in CBT among 170 students could be categorized as 2.35 low, $61 \%$ moderate, and 36.5\% high. Meanwhile, self-efficacy in PBT among students could be categorized as $4 \%$ low, $54 \%$ moderate, and $42 \%$ high; (2) Students' motivation to complete test could be categorized as 1\% low, $29.41 \%$ moderate, and 70\% high; (3) Testing effect, i.e. the test score and test completion time differences, showed that in term of completion time, the average in CBT was 55 minutes, while it was 59 minutes in PBT. It implied that students were faster in completing the test in CBT compared to PBT. In addition, the average test score in CBT was 53.16 and it was 46.36 in PBT, indicating that students who took CBT obtained higher score compared to those completing PBT; (4) Additionally, significance difference was found between students' score in CBT and in PBT. The aforementioned research investigated three aspects, namely self-efficacy in CBT and PBT, motivation, and testing effect. Meanwhile, according to various studies, many other factors have roles in this issue, such as computer self-efficacy, test anxiety (Lu et al, 2016), perceived playfulness, perceived ease of use, perceived usefulness and self-efficacy in operating computer (Maqableh et al, 2015).

Furthermore, Faculty of Psychology of Universitas Airlangga admits approximately 200 to 220 freshmen each year (Self Evaluation, 2016). For freshman students from various city of origin, and not all of them has experience of CBT, some psychological aspects such as test anxiety toward CBT, computer self-efficacy, and perceived ease of use might influence their performance in CBT. Based on this information and some previous studies, there are many other things to investigate further pertaining to the application of CBT and its relation with CBAAM. Particularly, relevant psychological factors such as test anxiety in CBT, computer self-efficacy, and perceived ease of use in completing CBT, especially for students in their first year. Such research is necessary because according to CBAAM, psychological factors have influence in the acceptance of CBT. The application of CBT both in Indonesian universities and schools still does not take in to consideration some related psychological aspects like students' anxiety toward the test, computer self-efficacy, perceived usefulness, etc. The initial findings that students were more anxious in CBT compared to conventional test indicates that such phenomenon indeed exists. Additionally, student's self-efficacy in operating computers to the extent that they can handle it when encounter some problems is a critical aspect in completing computer-based test. According to Terzis and Economides (2011), computer self-efficacy correlates with perceived ease of computer use. In addition to those two aspects, perceived ease of use is also one of author's interest. Perceived ease of use is the extent to which individuals believe that utilizing a system does not require a great deal of effort (Davis, 1989). It implies that when it is easy to use, freshmen will find it easy to accept CBT and it will not affect their performance.

Based on the explication above, author aimed to empirically observe psychological aspects such as test anxiety, computer-based self-efficacy, and perceived ease of use during CBT in first-year students.

\section{Test Anxiety}

Test anxiety is defined as a set of phenomenological, physiological, and behavioral response that accompany concern about possible negative consequences or failure on a test or similar evaluative situation (Zeidner, 1998; Lu et al, 2016). Test anxiety can also be defined as one feature of generic anxiety comprising cognitive attention process which interfere competent performance in academic or testing situation (Spielberger \& Vagg, 1995 cited 
in Shermis \& Lombard, 1998). CBT anxiety is conceptualized as apprehension or tension, fear, excessive worry, nervousness, and physiological arousal occurring prior to and during CBT (Balogun \& Olanrewaju, 2016).

Among some finding relevant to CBT and test anxiety is the finding of a study by Cassady et al (2015) that students who took online test experienced low level of anxiety during the test (Cassady \& Gridley, 2005). Lu and associates (2016) found that test anxiety had notable negative impact on performance in CAT.

\section{Computer Self Efficacy}

Self-efficacy is individual's evaluation and belief about their ability to effectively execute, do, or succeed in particular tasks (Bandura, 1997). It is one's belief in their own competence in dealing with a challenging task.

Computer self-efficacy (CSE) is defined as individual's perception on their capacity to operate computer (Compeau, D.; Higgins, 2014). There are some aspects of CSE, namely:

a. Magnitude: refers to the level of estimated/expected ability.

b. Strength: refers to one's level of confidence in finishing various tasks.

c. Generalizability: refers to the extent of individual's evaluation of their ability in mastering particular areas or domains in computer.

CSE is one's belief about own ability to operate computer. In this research, CSE is conceptualized as students' decision and individual confidence to effectively execute, complete, and succeed in CBT and other computerrelated activities (Balogun \& Olanrewaju, 2016). Computer self-efficacy is known to affect attitudes towards CAT (Lu et al, 2016).

\section{Perceived Ease of Use}

Perceived ease of use is the extent to which one believes that using a particular system would be free of effort (Davis, 1989). In a study by Terzis \& Economides (2011), perceived ease of use correlated with computer selfefficacy. Additionally, another study by Olafare (2011) found remarkable differences between male and females in perceived ease of use of CBT in Nigerian University.

\section{CBAAM (Computer-Based Assessment Acceptance Model)}

CBAAM is proposed by Terzis \& Economides (2011), incorporating the Technology Acceptance Model (TAM), the Theory of Planned Behavior (TPB), and the Unified Theory of Acceptance and Use of Technology (UTAUT). This model explains that (1) Goal Expectancy (GE) is affected by Content (C); (2) Perceived ease of use is significantly associated with CSE and perceived Facilitating Conditions (FC); (3) Perceived of Usefulness (PU) markedly correlates with content, goal expectancy, social influence, and perceived ease of use; (4) Perceived Playfulness is explained by perceived usefulness, perceived ease of use, content, and goal expectancy; (5) Behavioral intention to use CBA notably correlates with perceived playfulness and perceived ease of use. As described before, playfulness in a mediator for four constructs to the behavioral intention use CBA. In conclusion, perceived playfulness is a strong and significant variable.

Another model that discusses the acceptance of technology revealed by Alkist (2010) uses constructs from TAM by adding factors, individual differences namely self-efficacy, attitudes toward computers and anxiety. Alkist (2010) found that anxiety has a negative correlation to behavioral intentions using technology.

The model above shows that in the application of a technology, there are indeed some factors influencing the acceptance of that particular technology. In this case, the application of CBT, as one sort of technology application, is also bound to the same mechanism. Therefore, author aims to examine further the effect of some factors, namely test anxiety, computer self-efficacy, and perceived ease of use on the completion of CBT. 
Based on the literature review above and the findings of previous researches, the research questions are formulized as follow:

How is the level of test anxiety of first-year students in CBT?

How is the level of computer self-efficacy of first-year students in CBT?

How is the level of perceived ease of use of first-year students in CBT?

\section{Method}

This research is a descriptive study using quantitative approach.

\section{Research Variables}

The variables being investigated in current research are:

Test Anxiety is the degree of anxiety when taking an examination. It was measured using Test Anxiety Inventory to assess anxiety during a test. This variable was measured using test anxiety scale by Compeau, D. R., \& Higgins, C. A. (1995).

Computer Self-Efficacy is the degree of confidence in operating computer. This variable was measured using CSE scale by Compeau, D.R., \& Higgins, C.A. (1995).

Perceived Ease of Use is individual's perception that CBT is free of effort, or in other words, is easy to use. It was measured using Perceived Ease of Use scale by Davis (1989).

\section{Subject}

In term of subjects, this research involved the population of freshmen (admission year of 2017) of Faculty of Psychology who have taken a CBT for Individual Behavior and Mental Process course. Number of subjects are 203.

\section{Data Collection Instruments}

The scales include:

Computer Self-Efficacy scale by Compeau, D. R., \& Higgins, C. A. (1995). Reliability test resulted in $\alpha=0.784$.

Test Anxiety Inventory (TAI) by Taylor and Diane (2002). Reliability testing estimated $\alpha=0.901$.

Perceived Ease of Use scale by Davis (1989). The estimated reliability value was $\alpha=0.869$.

\section{Research Design and Procedures}

The procedure of current research is as follows:

Adapting scales for the three variables

Conducting a trial test

Analyzing and finalizing scales

Preparing a computer-based test for Individual Behavior and Mental Process course using an application via PsyChe which was developed by IT team of Faculty of Psychology Universitas Airlangga.

Freshmen who took the CBT for Individual Behavior and Mental Process course were then given the three scales which measure the investigated variables.

Inputting the data.

Data analysis and report writing. 


\section{Data Analysis}

This research is a descriptive study, hence the analysis resulted in descriptive data pertaining to the three investigated variables.

\section{Result}

The data from the survey to 203 first-year students about the three variables, which are test anxiety, CES, and perceived ease of use, was classified into three categories which were determined by author. The result then showed that in term of test anxiety during CBT, 16.74\% subjects were categorized as low, 76.26 was moderate, and the other $7 \%$ was identified as high. In term of computer self-efficacy in completing CBT, $28.57 \%$ student had low self-efficacy, $59.60 \%$ of them had moderate degree of self-efficacy, while the other $11.82 \%$ reported high self-esteem. In term of perceived ease of use during CBT, $2.46 \%$ students perceived low ease of use, $34.48 \%$ of the sample perceived moderate ease, and the remaining $63.05 \%$ perceived high degree of ease. In details, the descriptive data is shown in Table 2 to Table 6 below.

Table 1 Categorical Norm for Test Anxiety Score

\begin{tabular}{ll}
\hline Score & Category \\
\hline $\mathrm{X} \leq 40$ & Low \\
\hline $40<\mathrm{X} \leq 60$ & Moderate \\
\hline $60<\mathrm{X}$ & High \\
\hline
\end{tabular}

Table 2 Categorization of Test Anxiety Score of Freshmen in CBT

\begin{tabular}{lll}
\hline Category & Number & Percentage $(\%)$ \\
\hline Low & 34 & 16.74 \\
\hline Medium & 121 & 72.26 \\
\hline High & 15 & 7 \\
\hline
\end{tabular}

Table 3 Categorial Norm for Computer Self-Efficacy Score

\begin{tabular}{ll}
\hline Score & Category \\
\hline $\mathrm{X} \leq 40$ & Low \\
\hline $40<\mathrm{X} \leq 70$ & Moderate \\
\hline $70<\mathrm{X}$ & High \\
\hline
\end{tabular}

Table 4 Categorization of Computer Self-Efficacy Score of Freshmen in CBT

\begin{tabular}{lll}
\hline Category & Number & Percentage $(\%)$ \\
\hline Low & 58 & 28.57 \\
\hline Medium & 121 & 59.60 \\
\hline High & 24 & 11.82 \\
\hline
\end{tabular}

Table 5 Categorial Norm for Perceived Ease of Use Score

\begin{tabular}{ll}
\hline Score & Category \\
\hline $\mathrm{X} \leq 18$ & Low \\
\hline $18<\mathrm{X} \leq 30$ & Moderate \\
\hline $30<\mathrm{X}$ & High \\
\hline
\end{tabular}


Table 6 Categorization of Perceived Ease of Use Score of Freshmen in CBT

\begin{tabular}{lll}
\hline Category & Number & Percentage (\%) \\
\hline Low & 5 & $2.46 \%$ \\
\hline Medium & 70 & $34.48 \%$ \\
\hline High & 128 & $63.05 \%$ \\
\hline
\end{tabular}

\section{Discussion}

The descriptive statistic of test anxiety showed that the degree of anxiety of the majority (72.26\%) of first-year student in Faculty of Psychology was classified as moderate. There is $7 \%$ of the population who had high level of anxiety. This finding is understandable inasmuch as the use of CBT in university is a new experience for freshmen and they had not yet gotten used to it. Although some of them had taken CBT in their previous school for the Computer-Based National Examination (Ujian Nasional Berbasis Komputer/UNBK), the format and the program were different from the one used in this research hence it still caused anxiety. This finding is somewhat different from the study of Cassady et al (2015) which found that students who took online test experienced low anxiety during the test (Cassady \& Gridley, 2005). Therefore, test anxiety need to be considered in the application of CBT for first-year students.

Various research finding pertaining to test anxiety during CBT application can be seen, among others, in a study by Hong Lu and associates (2016) which found that anxiety during an examination had noteworthy negative impact on the performance in CAT. Another study concluded that test anxiety negatively correlated with performance in various testing or evaluative settings. Taking these effects into account, test anxiety during CBT on freshmen needs some attention, particularly at the level in which individual would need appropriate intervention.

The finding concerning computer self-efficacy during CBT indicated that about $28.57 \%$ students had low degree of self-efficacy, $59.60 \%$ students had moderate, and the other $11.87 \%$ had high self-efficacy. It showed that some freshmen were confident in operating computer during CBT in Faculty of Psychology Universitas Airlangga. However, the $28.57 \%$ who had low-level of efficacy would need some attention. Lack of confident in operating computer and navigating the application used in the CBT can influence students' anxiety during the examination. It is as reported in a research by Balogun and Olanrewaju (2016) which found that computer selfefficacy significantly predicted CBT anxiety. In addition, computer self-efficacy also happened to correlate with perceived ease of use (Terzis \& Economides, 2011).

In term of perceived ease of use, the result showed that $2.46 \%$ students perceived low degree of ease, $34.48 \%$ perceived moderate level of ease, while the other $63.05 \%$ deemed the test as of high ease. It implies that students regarded CBT was easy to use. Only $2.46 \%$ of them who had low ease perception of it. It also indicated that perceived ease of use remarkably associated with computer self-efficacy.

According to Computer Based Assessment Acceptance Model (CBAAM), Perception Ease of Use is significantly associated with Computer Self Efficacy. With the results of the two aspects that still exist in the low and medium for Computer Self Efficacy and Perception of Ease of Use, then this still need to get attention to new student in using computer based test. Meanwhile, according to Alkist (2010) found that anxiety has a negative correlation with behavioral intentions using technology. Another research, Lu and associates (2016) found that test anxiety had negative impact on performance in CAT. The results of test anxiety that still exist in the medium and high category so this also need to get attention to new student in using computer based test because high test anxiety will be impact several aspect as previous research. 


\section{Conclusion}

This research inferred that in term of test anxiety, $16.74 \%$ of the subjects was classified as low, $76.26 \%$ as moderate, and $7 \%$ as high. Concerning the computer self-efficacy while taking CBT, there was $28.57 \%$ of freshmen who had low degree efficacy, 59.60\% freshmen with moderate efficacy, and the other $11.82 \%$ with high level of efficacy. Meanwhile the result of measurement on perceived ease of use showed that $2.46 \%$ perceived low degree of ease, $34.48 \%$ perceived mediocre ease and the remaining $63.05 \%$ perceived high ease of use.

Some recommendation that this research may imply are:

1. Test anxiety during CBT is categorized as moderate and high for more than $50 \%$ of the population, hence intervention aiming to lower this degree of anxiety is necessary for the first-year students.

2. Regarding the computer self-efficacy and perceived ease of use, it is recommended for future research to study about their correlation with other variables such as performance in test.

\section{References}

Alkiş, N. (2010). Identifying Factors That Affect Students' Acceptance Of Web-Based Assessment Tools Within The Context Of Higher Education. Master Dissertation, Middle East Technical University.

Balogun, A. G., \& Olanrewaju, A. S., 2016, Role of computer self-efficacy and gender in computer-based test anxiety among undergraduates in Nigeria. Psychological Thought, 9(1), pp.58-66. https://doi.org/10.5964/psyct.v9i1.160

Bartram, D.S., 2001. Group plc, Thames Ditton, Surrey, UK dan Hambleton, Ronald K, University of Massachusetts at Amherst, USA. Computer-Based Testing and the Internet.

Bodmann, S.M. and Robinson, D.H., 2004. Speed and performance differences among computer-based and paper-pencil tests. Journal of Educational Computing Research, 31(1), pp.51-60.

Cassady, J.C. and Gridley, B.E., 2005. The effects of online formative and summative assessment on test anxiety and performance. The Journal of Technology, Learning and Assessment, 4(1). https://doi.org/10.1118/1.2336501

Clariana, R. and Wallace, P., 2002. Paper-based versus computer-based assessment: key factors associated with the test mode effect. British Journal of Educational Technology, 33(5), pp.593-602.

Compeau, D.R. and Higgins, C.A., 1995. Computer self-efficacy: Development of a measure and initial test. MIS quarterly, pp.189-211. Retrieved from http://www.jstor.org/stable/249688?seq=7

Davis, F.D., 1989. Perceived usefulness, perceived ease of use, and user acceptance of information technology. MIS quarterly, pp.319-340. https://doi.org/10.2307/249008

Lu, H., Hu, Y.P. and Gao, J.J., 2016. The effects of computer self-efficacy, training satisfaction and test anxiety on attitude and performance in computerized adaptive testing. Computers \& Education, 100, pp.45-55. https://doi.org/10.1016/j.compedu.2016.04.012

Mastuti,E. (2014) Pemanfaatan Teknologi Dalam Menyusun Evaluasi Hasil Belajar : Kelebihan dan kelemahan "Tes Online" untuk mengukur hasil belajar mahasiswa. Unpublished article disseminated at Konferensi Himpunan Evaluasi Pendidikan Indonesia, Bali.

Maqableh, M., Moh'd Taisir Masa, R.E. and Mohammed, A.B., 2015. The acceptance and use of computer based assessment in higher education. Journal of Software Engineering and Applications, 8(10), p.557.

Moon, J.W. and Kim, Y.G., 2001. Extending the TAM for a World-Wide-Web context. Information \& management, 38(4), pp.217-230. https://doi.org/10.1016/S0378-7206(00)00061-6

Olafare, F.O., 2011, Students'characteristics As Predictors Of Their Perceptions On The Effectiveness Of Computer-Based Test In Nigerian Universities. $\quad$ Retrieved from http://aiou.edu.pk/sab/pje/Pakistan\%20Journals/VOL-28,\%20ISSUE-II\%202011/2-

Ogunlade $\% 20 \& \% 20$ OLAFARE $\% 20$ Students $\% 20$ Characteristics $\% 20$ and $\% 20$ Perceptions $\% 20$ on $\% 20$ Computer. pdf. 
Endah Mastuti and Dewi Retno Suminar / Test Anxiety, Computer Self Efficacy, And Perceived.....

Redecker, C., 2013. The use of ICT for the assessment of key competences. Joint Research Centre of the European Commission Scientific and Policy Report. https://doi.org/10.2791/87007

Shermis, M.D. and Lombard, D., 1998. Effects of computer-based test administrations on test anxiety and performance. Computers in Human Behavior, 14(1), pp.111-123.. https://doi.org/10.1016/S0747$\underline{5632(97) 00035-6}$

Self Evaluation . 2016. Annual Report Faculty of Psychology, AIrlangga University

Terzis, V. and Economides, A.A., 2011. The acceptance and use of computer based assessment. Computers \& Education, 56(4), pp.1032-1044. https://doi.org/10.1016/j.compedu.2010.11.017 